\title{
Analysis of Usage Factors of Restaurant Customers in Traditional Markets
}

\author{
Choongsoo Lee ${ }^{1}$ \\ ${ }^{1}$ Department of International Logistics \& Trade, Gwangju University, Gwangju, South Korea \\ Correspondence: Choongsoo Lee, Department of International Logistics \& Trade, Gwangju University, Gwangju, \\ South Korea. Tel: 82-10-2271-9762. E-mail: cslee@gwangju.ac.kr
}

Received: April 9, 2020

Accepted: May 9, 2020

Online Published: May 23, 2020

doi:10.5430/rwe.v11n2p36

URL: https://doi.org/10.5430/rwe.v11n2p36

\begin{abstract}
Background/Objectives: The traditional market, which was at the center of the domestic distribution industry, is undermined by the trend of large size, specialization, and service. Successful cases are often seen through the coexistence of traditional markets and dining services. In the traditional market, eating out is the main product, and the customer's preference is very high.

Methods/Statistical analysis: The purpose of this study is to summarize the usage factors that are important to customers of traditional market restaurants, and to analyze the priorities of the usage factors through the Analytic Hierarchy Process (AHP). In this study, we analyzed the level1 factors of traditional market restaurant customers into traditional market environment, restaurant environment, and food feature, and proposed an analysis model that classifies detailed factors of each factor.

Findings: The analysis results are as follows. First, Level 1 showed relatively high importance in order of food feature (0.41), restaurant environment (0.33), and traditional market environment (0.26). Second, the usage factor of food feature had high priority of flavor and price. In the restaurant environment, cleanliness and kindness were high priority. In the traditional market environment, cleanliness and accessibility were important. Third, overall priority was high in order of flavor, price, and restaurant cleanliness.
\end{abstract}

Improvements/Applications: These results will help to improve the management of vulnerable and small traditional market restaurants.

Keywords: analytic hierarchy process, traditional markets, usage factors, relative importance, priority

\section{Introduction}

Korea's traditional market is a place where local people's traditional culture and emotions stand out, and the products sold are the trading centers of local specialties such as agricultural and livestock products produced in the region, located close to local residents, the main market for small and medium- sized merchants, and middle and low income groups. It has performed various functions and roles in the area of local economy, such as providing customers with the opportunity to purchase low prices of goods (Kim, 2010). Until the 1980s, traditional markets had served as a center for distribution spaces for buying agricultural and livestock products, daily necessities and industrial products, but have declined due to changes in the distribution market environment and consumer purchasing patterns (Shim, 2013). 90 second half's large of distributors hypermarket openings with competitive SSM (the Super Supermarket) new of chained supermarkets were to enter the commercial alleys. The emergence of hypermarkets and SSMs poses a threat to traditional markets, leading to sluggish sales and reduced number of stores in traditional markets. The government has supported the traditional market with the facilities modernization and management modernization projects.

Even though the traditional market, which was at the center of the domestic distribution industry, is not able to escape the small scale due to the trend of enlargement, specialization, and service, several successful cases show the possibility of win-win development of the traditional market and dining service. As can be seen from the success story of Gwangjang Market in the center of Seoul, Gwangjang Market has emerged as a travel or tourist attraction for many Koreans and foreign tourists, and its flagship products are relatively inexpensive enough to lead to attracting customers. It is securing competitiveness. Food in this market enjoys its status as the second flagship product among specialty products, but preference has become the main product from the customer's point of view (Lee, 2014). The harmonious 
coexistence model of traditional market and eating out service shows the possibility of success model of traditional market activation. Shim's research (Shim, 2013) in traditional markets prefer to purchase results of relevant studies by product satisfaction and revisit help, intent higher customer satisfaction in the traditional market Visitors to revisit also was found to be higher in the traditional market Visitors Studies have confirmed that food is the number one item that affects satisfaction.

Although numerous studies have been conducted to improve the soundness of the food industry development, most of the studies have been conducted on corporate restaurants such as hotel restaurants, family restaurants, and fast food. And it was targeted to specific fields such as Korean, Western, Chinese and Japanese. It is now time for the necessity and importance of research to be of practical help to relatively small traditional market catering companies. This study presents basic data that can help to improve the management of traditional market restaurants by studying the weak and small restaurants in traditional markets. The purpose of this study is to summarize the usage factors that customers of traditional market restaurants use, and to analyze their priorities.

\section{Literature Research}

Food is a product that attracts customers because it provides fun and functions as a cultural activity (Jeong, 2011). According to data published by Hanwha day's, foods sold in traditional markets generally include stir-fried rice cake, dumplings, sundae, Chinese pancake, stew, fish cakes, tempura, sweet \& sour chicken, giblets, rice cake, sashimi, and noodles (Hanwha, 2019). Park's recent work (Park, 2016) on food argues that food is a big part of tourism and that tourists value traditional markets most importantly among food tourism resources. Previous studies on traditional markets include customer satisfaction, revisit and loyalty of traditional markets (Hong, 2013), traditional market image of culture tourism type (Lee and Kim, 2012), evaluation of tourism attractiveness of traditional markets (Kim and Heo, 2012), and comparison of the importance and satisfaction of the selection attributes (Kim and Heo, 2012). All of them are limited to the retail market function of traditional markets, and no studies have been conducted to include the food service provided in and outside the traditional market as a selection attribute or to consider the relationship with the food service.

Among the studies that analyzed consumer's selection attributes related to food regardless of the traditional market, HMR(Home Meal Replacement) studies (Jeong and Lee, 2015; Ju, 2012) analyzed attributes such as hygiene, origin labeling, health, brand reliability, safety, store reliability, taste, quality, appearance, convenience, price adequacy, menu diversity and worker description. The Hamburger study (Park, 2010) analyzed nutrition and health, quality and safety, taste, quantity, appearance, price, calories, origin, menu variety, surrounding reputation and promotion. Local food research (Jung and Hwang, 2014; Yang and Oh, 2009) analyzed taste, nutrition, freshness, quality, health, seasonality, shape, color, recipe, convenience and variety of local food.

The purpose of this study is to derive the discriminating factors that help manage the restaurant business by analyzing the factors used by the restaurant customers in the traditional market using AHP (Analytic Hierarchy Process).

\section{Experimental Design and Results}

\subsection{AHP Overview}

The AHP (Analytic Hierarchy Process) is a method of producing more objective and scientific results by converting subjective and qualitative data into quantitative data in decision making. AHP is a multi-criteria decision model that hierarchically expresses decision problems and prioritizes alternatives based on decision makers' decisions (Saaty, 1980; Saaty and Vargas, 1982).

AHP is the most widely used theory of decision theory because it focuses on the experience and intuition of decision makers and can handle not only quantitative information but also qualitative information that is difficult to deal with in decision making. In addition, the consistency index increases the reliability of the test results and weights the test criteria to analyze the sensitivity of the situation and changes related to the results.

The priority analysis model used in this study is performed by four analysis processes as shown in [Figure 1]. The analysis process consists of defining factors for the analysis and structural organization of the factors, constructing a structured dual comparison matrix based on the survey results, calculating the relative weights between the factors, and weighting each element to prioritize the sub-elements. It is composed of the steps (Saaty, 1980; Saaty and Vargas, 1982). 


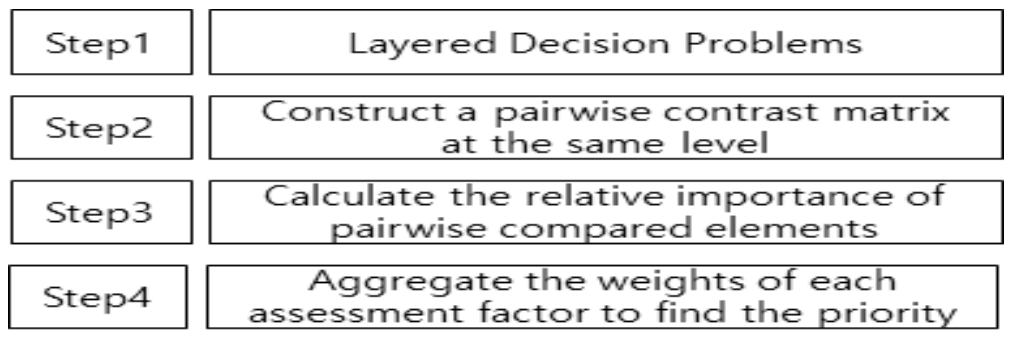

Figure 1. AHP analysis process

\subsection{Analytical Model}

In this study, the levell factors of traditional market restaurant customers are classified into traditional market environment, restaurant environment, and food feature through the existing researches, and the level 2 of each factor is summarized as in [Table 1].

Table 1. Definition of usage factors

\begin{tabular}{|c|c|c|}
\hline $\begin{array}{c}\text { Usage } \\
\text { Factors } \\
\text { (Level 1) }\end{array}$ & $\begin{array}{l}\text { Detailed Usage } \\
\text { Factors(Level 2) }\end{array}$ & Description of detailed usage factors \\
\hline \multirow{4}{*}{$\begin{array}{c}\text { traditional } \\
\text { market } \\
\text { environment }\end{array}$} & accessibility & market accessibility \\
\hline & parking convenience & size of parking space \\
\hline & cleanliness & $\begin{array}{l}\text { internal and external cleanliness of the } \\
\text { market }\end{array}$ \\
\hline & friendliness & market familiarity \\
\hline \multirow{4}{*}{$\begin{array}{c}\text { restaurant } \\
\text { environment }\end{array}$} & kindness & employee kindness \\
\hline & cleanliness & $\begin{array}{c}\text { internal and external cleanliness of the } \\
\text { restaurant }\end{array}$ \\
\hline & display & showcase inside the restaurant \\
\hline & diversity & variety of food types \\
\hline \multirow{4}{*}{ food feature } & flavor & food flavor \\
\hline & freshness & freshness of food ingredients \\
\hline & quantity & plenty of food \\
\hline & price & cheap degree of food price \\
\hline
\end{tabular}

In order to measure the relative importance of AHP, a questionnaire was compared to compare the relative importance between the selection attributes of the same level (layer). First, compare the relative importance between the usage factors at the same level as Level 1, and compare the relative importance between the level 2 detailed users at Level 1. A questionnaire for measuring the relative importance between each indicator was designed as shown in [Table 2]. [Table 3] summarizes the criteria for indicating preference for pairwise teaching. The number of paired bridges is $\mathrm{nC} 2$, which is designed so that the number of questions in the questionnaire is not missed (Tubosun, 2019); (Ukwayi et al., 2019).

As a data collection method, an e-mail was sent to 200 users of traditional market restaurants and received 68 questionnaires. Among them, AHP analysis was conducted on 59 questionnaires with missing values in the bi-contrast items and 59 questionnaires that were removed from the non-logical questionnaire by checking them. [Table 4] summarizes the characteristics of the survey respondents. 
Table 2. Questionnaire that measures relative importance between usage factors

\begin{tabular}{lllllllllll}
\hline Usage & \multicolumn{1}{c}{ Rating scale } & Usage \\
factor & 9 & 7 & 5 & 3 & 1 & 3 & 5 & 7 & 9 & factor \\
\hline flavor & \multicolumn{1}{c}{$\sqrt{ }$} & & & & & & & price \\
\hline
\end{tabular}

Table 3. Preference of pair comparisons

\begin{tabular}{ll}
\hline value & meaning \\
\hline 1 & A and B are equally preferred \\
\hline 3 & A is weakly favored than B \\
\hline 5 & A is strongly more important than B \\
\hline 7 & A is much more strongly or demonstrably important than B \\
\hline 9 & A is absolutely more important than B \\
\hline
\end{tabular}

Table 4. General characteristics of the survey responder

\begin{tabular}{cccc}
\hline \multirow{2}{*}{ gender } & characteristic & frequency $(\mathrm{n}=59)$ & percent $(\%)$ \\
\cline { 2 - 4 } & male & 24 & 40.6 \\
\hline \multirow{2}{*}{ age } & female & 35 & 59.4 \\
\cline { 2 - 4 } & $30 \sim 39$ & 11 & 18.6 \\
\cline { 2 - 4 } & $40 \sim 49$ & 19 & 32.2 \\
\hline
\end{tabular}

Table 5. The relative weight and priority of the calculated usage factors

Level 1

Level 2

Total

\begin{tabular}{|c|c|c|c|c|c|c|c|}
\hline Usage Factors & Weight & Priority & $\begin{array}{c}\text { Detailed Usage } \\
\text { Factors }\end{array}$ & Weight & Priority & Weight & Priority \\
\hline \multirow{4}{*}{$\begin{array}{c}\text { traditional } \\
\text { market } \\
\text { environment }\end{array}$} & \multirow{4}{*}{0.26} & \multirow{4}{*}{3} & accessibility & 0.28 & 2 & 0.0728 & 9 \\
\hline & & & $\begin{array}{c}\text { parking } \\
\text { convenience }\end{array}$ & 0.25 & 3 & 0.065 & 11 \\
\hline & & & cleanliness & 0.31 & 1 & 0.0806 & 7 \\
\hline & & & friendliness & 0.16 & 4 & 0.0416 & 12 \\
\hline \multirow{4}{*}{$\begin{array}{c}\text { restaurant } \\
\text { environment }\end{array}$} & \multirow{4}{*}{0.33} & \multirow{4}{*}{2} & kindness & 0.26 & 2 & 0.0858 & 6 \\
\hline & & & cleanliness & 0.3 & 1 & 0.099 & 3 \\
\hline & & & display & 0.24 & 3 & 0.0792 & 8 \\
\hline & & & diversity & 0.2 & 4 & 0.066 & 10 \\
\hline \multirow{4}{*}{ food feature } & \multirow{4}{*}{0.41} & \multirow{4}{*}{1} & flavor & 0.29 & 1 & 0.1189 & 1 \\
\hline & & & freshness & 0.22 & 3 & 0.0902 & 4 \\
\hline & & & quantity & 0.21 & 4 & 0.0861 & 5 \\
\hline & & & price & 0.28 & 2 & 0.1148 & 2 \\
\hline
\end{tabular}




\subsection{Experiment Results and Analysis}

Normalized weights were calculated to obtain the relative importance of each user factor by constructing a pairwise comparison matrix based on the geometric mean of each individual's questionnaire. By arithmetically averaging this, relative weights of Level 1 and Level 2 were obtained as shown in [Table 5]. AHP has a device called Consistency Rate (CR) that can verify the logical consistency of the evaluator's judgment, thereby increasing the reliability of the results. If the respondents responded with perfect match at the pairwise bridge, the CR would be 0 , but in reality, it would not be a perfect match, and if the CR was 0.1 (less than 10\%), the consistency would be considered good. If it is inconsistent and is 0.2 or more, it is considered to be inconsistent and needs to be reexamined. This study proved that the weights of all the indicators are consistent because the overall consistency ratio is 0.0912 , which is less than 0.1 (Tao and Chao, 2019); (Tatli, 2018).

The weights and priorities of Level 1 and Level 2 have been measured to measure the relative importance among the factors used by traditional market restaurant users by using the AHP method. First, Level 1 showed relatively high importance in order of food feature (0.41), restaurant environment (0.33), and traditional market environment $(0.26)$. Second, the usage factor of food feature had high priority of flavor and price. In the restaurant environment, cleanliness and kindness were high priority. In the traditional market environment, cleanliness and accessibility were important. Third, overall priority was high in order of flavor, price, and restaurant cleanliness.

\section{Conclusion}

In this study, we propose an AHP analysis model that derives the factors of use of traditional market users from previous studies and analyzes them comprehensively. In order to analyze the priorities of traditional market restaurants, we designed a user factor analysis model, conducted a survey, and performed relative weight analysis and consistency ratio analysis.

First, Level 1 showed relatively high importance in order of food feature (0.41), restaurant environment (0.33), and traditional market environment (0.26). Visitors in traditional market restaurants use food rather than market and store. This is to find a restaurant that is good at a particular food rather than a traditional market, and creating a lot of such restaurants is a way to revitalize the traditional market.

Second, the food feature usage factors had high priority in order of flavor, price, freshness, and quantity. Traditional market food appears to be used because it is delicious and cheap, and freshness is the third priority. The four usage factors in the food feature are all important factors to be ranked in the top 5, so it is a factor that requires much attention in traditional market restaurants. In the restaurant environment, priority was given in order of cleanliness, kindness, display, and diversity. The cleanliness that mattered most at any restaurant was the most important factor, and the service-friendly kindness. Display and diversity are relatively low priorities. In the traditional market environment, priority was given in order of cleanliness, accessibility, parking convenience, and friendliness. The highest priority for the traditional market environment and restaurant environment seems to be due to the recent global corona virus.

Third, the overall priority was high in order of flavor, price, restaurant cleanliness, freshness, quantity, kindness. The high level of detail use of food features is considered to be important for the taste of food itself and for its low price.

Since the priority of cleanliness and freshness is high, education and management necessary for on-site practical work on personal hygiene, food hygiene, and food safety of traditional market food workers should be made to improve the hygiene of food in traditional market and the quality satisfaction of ingredients. Since this study was conducted by an acquaintance of an author who has experience using traditional markets, it is considered that there is a limit to generalizing the results.

\section{Acknowledgment}

This study was conducted by research funds from Gwangju University in 2020.

\section{References}

Hanwha, D. (2019). Traditional market gourmet map. Retrieved from http://blog.hanwhadays.com

Hong, G. G. (2013). The effects on consumer satisfaction and loyalty in renewed traditional retail market renewal in small and mid-sized cities - the case of Yeongchun public retail market in Yeongchun. The Architectural Institute of Korea, 29(3), 275-283.

Jeong, H. K. (2011). A study on influencing factors of travelers' unplanned eating-out behavior [Dissertation]. Dong-A University.

Jeong, Y. G., \& Lee, I. S. (2015). Importance-performance and willingness to purchase analyses of home meal 
replacement using eco-friendly food ingredients in undergraduates according to gender. J Korean Soc Food Sci Nutr, 44, 1873-1880.

Ju, S. Y. (2012). Study on importance-performance analysis regarding selective attributes of home meal replacement (HMR). J Korean Soc Food Sci Nutr, 41, 1639-1644.

Jung, W. S., \& Hwang, S. J. (2014). A study on the perception, importance and satisfaction with local traditional food among university students: Focused on Kyungsan city. Korean J Culinary Res, 20, 120-132.

Kim, D. Y. (2010). An effect of traditional market customer's choice attribute on the preference and revisit [Master Thesis]. Jeju University.

Kim, H. B., \& Kim, H. (2012). Difference of purchasing behavior by types of retail store and importance-performance analysis market selection attributes; focused on improvement of traditional market competitiveness. The Korea Contents Society, 12(9), 311-324.

Kim, H. R., \& Heo, J. W. (2012). The relationships among tourist attractiveness, satisfaction, and behavioral intention of culture tourism oriented traditional markets. Korea Academic Society Tourism Management, 26(6), 141-155.

Lee, J. H. (2014). Success factors for developing urban and rural traditional marketplace as a tourist attraction: The case of Seoul Gwangjang market and Jangheung Toyo(Saturday) market. Journal of the Economic Geographical Society of Korea, 17(2), 366-384.

Lee, J. J., \& Kim, H. R. (2012). The relationship of festival environmental cues and image of culture tourism oriented traditional marketplace. Journal of Korea Wellness, 7(1), 309-321.

Park, H. R. (2010). A study on the importance and satisfaction of the attributes for the product development of hamburger [MS Thesis]. Chung-Ang University, pp. 83-90.

Park, S. J. (2016). A study on a classification of culinary tourism resources and a comparison of importance of culinary tourism resources [MS Thesis]. Woosuk University, pp. 38-42.

Saaty, T. L., \& Vargas, L. G. (1982). The logic of priorities. London: kluwer-Nijhoff Pulishing.

Saaty, T. L. (1980). The analytic hierarchy process. New York: McGraw-Hill.

Shim, W. S. (2013). The study of relations between customer satisfaction by purchasing favored products and revisit intention at traditional markets space. Cultural Industry Research, 13.

Tao, K., \& Chao, Y. (2019). Rethinking port role as transport corridor under symbiosis theory-case study of China-Europe Trade Transportation. Policy, 8(1), 51-61.

Tatli, H. (2018). Multiple determinants of household natural gas demand: A panel data analysis in OECD countries. Asian Development Policy Review, 6(4), 243-253.

Tubosun, B. V. (2019). Strategic planning assessment of tertiary institutions in Kano State, Nigeria. International $\begin{array}{lllll}\text { Journal of } & \text { Social } & \text { Sciences } & \text { Perspectives, } & 5(1),\end{array}$ https://doi.org/https://doi.org/10.33094/7.2017.2019.51.22.29

Ukwayi, J. K., Okpa, J. T., \& Akwaji, F. (2019). Trends in illicit drug trafficking in Nigeria: Highlighting the imperative of raising the red flag. American Journal of Social Sciences and Humanities, 4(1), 25-37.

Yang, T. S., \& Oh, M. C. (2009). A study on impacts of selection attribute of Jeju local folklore food on customers' behaviors: Focusing on customer satisfaction, re-visit, and word of mouth of Jeju tourists. J Kor Soc Food Sci Nutr, 38, 636- 643. 